\title{
Sellar and parasellar tumor removal without discontinuing antithrombotic therapy
}

\author{
Yoshikazu Ogawa, MD, PhD, ${ }^{1}$ and Teiji Tominaga, MD, PhD² \\ 'Department of Neurosurgery, Kohnan Hospital; and 2Department of Neurosurgery, Tohoku University Graduate School of \\ Medicine, Sendai, Miyagi, Japan
}

\begin{abstract}
OBJECT Treatment with dual antiplatelet agents associated with coronary stenting procedures and long-term anticoagulant therapy is increasingly common, but the treatment carries risks during surgical procedures. Evidence-based recommendations have proposed discontinuation of antithrombotic treatment or introduction of bridging therapy in some procedures less invasive and with lower risk of bleeding. However, neurosurgical procedures without discontinuation of antithrombotic treatment and perioperative management have received little investigation.
\end{abstract}

METHODS Between October 2008 and January 2014, 15 consecutive patients (11 males and 4 females; age range 51-75 years [mean 68.2 years]), with sellar and parasellar tumors were treated through the transsphenoidal approach without discontinuation of antithrombotic therapy. Clinical data were compared with another 15 patients, who underwent transsphenoidal surgeries without preoperative antithrombotic therapy.

RESULTS Gross-total removal of the tumor or total aspiration of the content of Rathke's cleft cyst was achieved in 13 patients, and subtotal removal was achieved in 1 patient with a small remnant in the cavernous sinus. No difference was found in intraoperative bleeding between the antithrombotic agent group and the control group (mean $255 \mathrm{ml} v 215 \mathrm{ml}$, Mann-Whitney U-test, $p=0.547$ ), and no patient required transfusion. No difference was found in operation time between the antithrombotic agent group and the control group (167.8 minutes vs 150.0 minutes, Mann-Whitney U-test, $p=$ 0.262). All patients were discharged on postoperative Day 12 without neurological deficits.

CONCLUSIONS The present study suggests that discontinuation of antithrombotic therapy may be unnecessary before the typical transsphenoidal surgery. Large randomized clinical trials at multiple centers are needed to confirm these findings.

http://thejns.org/doi/abs/10.3171/2014.9.JNS141088

KEY WORDS anticoagulant; antiplatelet; antithrombotic therapy; discontinuation; operation; transsphenoidal approach; pituitary surgery

$\mathrm{L}$ ONG-TERM anticoagulant therapy is currently administered to more than 6 million patients for the treatment of atrial fibrillation, deep venous thrombosis, various valve diseases, and malignancy-related syndromes.${ }^{45}$ In addition, recent advances in coronary stenting procedures have rapidly increased the need for treatment with dual antiplatelet agents. ${ }^{5}$ However, about $10 \%$ of these patients will undergo invasive procedures every year, which will require temporary discontinuation of the antithrombotic therapy or some bridging therapy.,5,21,28 Evidence-based recommendations have been proposed to deal with this complicated countermeasure in some less invasive procedures with lower risk of bleeding, such as dental procedures or cataract operations. ${ }^{1-3,6-19,21-25,29,30,32-38}$ How- ever, procedures without discontinuation of antithrombotic treatment have received little attention, ${ }^{39}$ and the perioperative period in neurosurgical procedures has also been less well studied. . $^{20,26,27,31,40-42}$

The present clinical study retrospectively analyzed a series of transsphenoidal surgeries performed without discontinuation of antithrombotic therapy for comparison with the same number of transsphenoidal surgeries performed in the absence of antithrombotic therapy.

\section{Methods}

Between October 2008 and January 2014, 15 consecutive patients (11 males and 4 females; age range 51-75 
years [mean 68.2 years]) with sellar and parasellar tumors were treated via a transsphenoidal approach by a single surgeon (Y.O.), accounting for $2.51 \%$ of all transsphenoidal operations during the same period. The histological diagnoses were pituitary adenoma $(\mathrm{n}=9)$, Rathke's cleft cyst $(n=4)$, clival chordoma $(n=1)$, and biopsy of skull base pachymeningitis $(\mathrm{n}=1)$. Eleven patients were treated with antiplatelet agents and 4 with anticoagulant agents. The prothrombin time-international normalized ratio (PT-INR) was measured preoperatively before administering anticoagulant agents, which verified that all PT-INRs were within the required limits (Table 1). The patients continued to take antithrombotic agents until the morning of surgery, and, after verification of the absence of ischemic and/or hemorrhagic complications on the morning of postoperative Day 1, administration of antithrombotic agents was restarted. All operations were performed via sublabial mucosal incisions, and the closest attention was paid to preserve the arachnoid plane at the top of the lesions in expectation of postprocedural hemostasis by compressive pressure of CSF spaces. Extended transsphenoidal surgeries through the subarachnoid spaces and giant pituitary adenomas with a maximum diameter larger than $40 \mathrm{~mm}$ were excluded due to the presumptive high risk of after-bleeding. Clinical data were compared with the data of 15 patients who underwent transsphenoidal surgery without preoperative antithrombotic therapy between December 2013 and January 2014. The surgical policy was explained preoperatively to the patients, and written informed consent was obtained. The overall study design was approved by the ethics committee of Kohnan Hospital. Statistical comparisons used Mini Statmate software (ATMS Co., Ltd.), and p values $<0.05$ were regarded as significant.

\section{Results}

Gross-total removal of the tumor or total aspiration of the content of the Rathke's cleft cyst was achieved in 13 patients, and subtotal removal was achieved in 1 patient with a small remnant in the cavernous sinus. Aggressive removal was suspended in 1 patient because intraoperative histological examination had revealed pachymeningitis. Head CT scanning performed the morning of postoperative Day 1 revealed that most cavities of the sellae were occupied with CSF, so-called empty sellae. No patient experienced massive abnormal bleeding throughout the hospital course. Comparison of the antithrombotic agent group and the control group found no difference in preoperative tumor volume (antithrombotic agent group vs control: $2.45 \mathrm{ml}$ vs $3.18 \mathrm{ml}, \mathrm{p}=0.48$ ), but patients were older in the antithrombotic agent group (63.32 years vs 57.73 years, $p=0.029$ ). Opening of the ipsilateral cavernous sinus occurred in 4 patients in the antithrombotic agent group, but hemostasis was achieved in all patients with common techniques, such as compression with cotton flakes and/or point-by-point coagulation. In the antithrombotic agent group, bleeding varied from $100 \mathrm{ml}$ to $485 \mathrm{ml}$ (mean $255 \mathrm{ml}$ ), and no patient required transfusion, even after open cavernous sinus surgeries. Comparison of the antithrombotic agent group and the control group found no difference in intraoperative bleeding $(255 \mathrm{ml}$ vs 215 $\mathrm{ml}$, Mann-Whitney U-test, $\mathrm{p}=0.547$ ). Operation time varied in the antithrombotic agent group from 114 minutes to 241 minutes (mean 167.8 minutes). Comparison of the antithrombotic agent group and the control group found no difference in operation time (167.8 minutes vs 150.0 minutes, Mann-Whitney U-test, $\mathrm{p}=0.262$ ) (Tables 2 and 3). All patients were discharged on postoperative Day 12 without neurological deficits.

TABLE 1. Profiles of patients undergoing antithrombotic therapy

\begin{tabular}{|c|c|c|c|c|c|}
\hline $\begin{array}{l}\text { Case } \\
\text { No. }\end{array}$ & $\begin{array}{c}\text { Age (yrs) } \\
\text { Sex }\end{array}$ & Histology & Antithrombotic Agent & Reason & Remarks \\
\hline 1 & $74, \mathrm{M}$ & Atypical adenoma & Aspirin $100 \mathrm{mg}$ & ACA stenosis & Opening of CS \\
\hline 2 & $67, \mathrm{M}$ & Rathke's cleft cyst & Aspirin $100 \mathrm{mg}$ & Coronary stent & \\
\hline 3 & $75, \mathrm{M}$ & Plurihormonal adenoma & Aspirin $100 \mathrm{mg}$ & Angina & Opening of CS \\
\hline 4 & $71, \mathrm{~F}$ & Rathke's cleft cyst & Clopidogrel 25 mg & MCA stenosis & \\
\hline 5 & $72, \mathrm{M}$ & Rathke's cleft cyst & Aspirin 81 mg & AMI & \\
\hline 6 & $75, \mathrm{~F}$ & Acromegaly & PT-INR 1.34 & Paroxysmal AF & \\
\hline 7 & $62, \mathrm{M}$ & Plurihormonal adenoma & Aspirin $100 \mathrm{mg}$ & Angina & \\
\hline \multirow[t]{2}{*}{8} & \multirow[t]{2}{*}{$66, M$} & \multirow[t]{2}{*}{ Rathke's cleft cyst } & Aspirin $100 \mathrm{mg}$ & Coronary stent & \\
\hline & & & Ticlopidine 200 mg & Y graft \& FF bypass & \\
\hline 9 & $67, \mathrm{~F}$ & Gonadotroph cell adenoma & Cilostazol $200 \mathrm{mg}$ & Aortic dissection & \\
\hline 10 & $72, \mathrm{M}$ & Mixed GH \& PRL adenoma & Aspirin $100 \mathrm{mg}$ & Repeat angina & Suspended clopidogrel \\
\hline 11 & $51, \mathrm{M}$ & Pachymeningitis & PT-INR 2.01 & AVR, AV block (3) & Temporary pacemaker \\
\hline 12 & $69, \mathrm{M}$ & Plurihormonal adenoma & Aspirin $100 \mathrm{mg}$ & Coronary stent & Opening of CS \\
\hline 13 & $70, \mathrm{M}$ & Null cell adenoma & Aspirin $100 \mathrm{mg}$ & Angina & \\
\hline 14 & $71, \mathrm{~F}$ & Corticotroph cell adenoma & PT-INR 1.55 & DVT & \\
\hline 15 & $61, \mathrm{M}$ & Chordoma & PT-INR 1.95 & Paroxysmal AF & Opening of CS \\
\hline
\end{tabular}

$\mathrm{ACA}=$ anterior cerebral artery; $\mathrm{AF}=$ atrial fibrillation; $\mathrm{AMI}=$ acute myocardial infarction; $\mathrm{AV}=$ atrioventricular; $\mathrm{AVR}$ = aortic valve replacement; $\mathrm{CS}=$ cavernous sinus; $\mathrm{DVT}=$ deep venous thrombosis; $\mathrm{FF}=$ femoral-femoral; $\mathrm{GH}=$ growth hormone; $\mathrm{MCA}=$ middle cerebral artery; $\mathrm{PRL}=$ prolactin; PT-INR = prothrombin time-international normalized ratio. 
TABLE 2. Results of surgery with antithrombotic therapy

\begin{tabular}{clcccc}
\hline Case No. & \multicolumn{1}{c}{ Histology } & Vol $(\mathrm{ml})$ & Blood Loss $(\mathrm{ml})$ & Operation Time $(\mathrm{mins})$ & Removal Rate $(\%)$ \\
\hline 1 & Atypical adenoma & 1.89 & 130 & 164 & 100 \\
\hline 2 & Rathke's cleft cyst & 0.86 & 230 & 114 & 100 \\
\hline 3 & Plurihormonal adenoma & 1.16 & 125 & 149 & 100 \\
\hline 4 & Rathke's cleft cyst & 0.94 & 485 & 162 & 100 \\
\hline 5 & Rathke's cleft cyst & 0.09 & 100 & 137 & 100 \\
\hline 6 & Acromegaly & 3.04 & 150 & 127 & 100 \\
\hline 7 & Plurihormonal adenoma & 4.39 & 290 & 228 & 100 \\
\hline 8 & Rathke's cleft cyst & 0.5 & 125 & 123 & 100 \\
\hline 9 & Gonadotroph cell adenoma & 0.6 & 300 & 144 & 100 \\
\hline 10 & Mixed GH \& PRL adenoma & 5.46 & 460 & 171 & 100 \\
\hline 11 & Pachymeningitis & & 115 & 241 & Biopsy \\
\hline 12 & Plurihormonal adenoma & 9.01 & 425 & 131 & 100 \\
\hline 13 & Null cell adenoma & 2.89 & 205 & 195 & 100 \\
\hline 14 & Corticotroph cell adenoma & 0.01 & 290 & 194 & 100 \\
\hline 15 & Chordoma & 3.4 & 400 & & 96 \\
\hline
\end{tabular}

\section{Discussion}

The risk of thrombosis has been estimated for some systemic diseases or conditions. ${ }^{4,5,28}$ Recent venous thrombosis (within 1 month), repeated arteriovenous thrombophilia, and mitral valve disease carry higher risks of thrombosis, whereas old venous thrombosis ( $>3$ months) and nonvalvular atrial fibrillation involve lower risks of thrombosis. ${ }^{21}$ Invasive procedures also involve the risk of bleeding in patients receiving antithrombotic therapy. Orthopedic hip procedures and colon polypectomy have higher risks of bleeding, whereas dental procedures, cataract surgery, dermatological procedures, and surgery for carpal tunnel syndrome have lower risks of bleeding. ${ }^{4}$ The factors of thrombogenesis and fibrinolysis have been specifically considered in some invasive procedures, resulting in evidence-based recommendations for discontinuation of antithrombotic therapy or introduction of bridging ther- apy., ${ }^{4,5,21,28} \mathrm{~A}$ large randomized study was reported recently in patients receiving or not receiving aspirin therapy who underwent noncardiac surgery. The study revealed that there was not an increase in cardiac or cerebrovascular events in the patients who discontinued the antiplatelet therapy compared with those who did not, although there was a slight increase in the amount of hemorrhage in the group that stayed on antiplatelet therapy. ${ }^{12}$ However, in this study more than two-thirds of the patients had received bridging anticoagulant therapy, so the true result with or without discontinuation of antiplatelet therapy in perioperative period remains unsolved.

Very few clinical studies have considered perioperative management of neurosurgical patients receiving antithrombotic therapy except for antiplatelet therapies incorporated in intravascular treatments. ${ }^{20,26,27,31,42}$ Temporary discontinuation of antithrombotic therapy or introduction

TABLE 3. Results of surgery without antithrombotic therapy

\begin{tabular}{cclrccc}
\hline Case No. & Age (yrs), Sex & \multicolumn{1}{c}{ Pathology } & Vol (ml) & Blood Loss $(\mathrm{ml})$ & Operation Time (mins) & Removal Rate (\%) \\
\hline 16 & $28, \mathrm{~F}$ & Lactotroph cell adenoma & 0.05 & 135 & 156 & 100 \\
\hline 17 & $54, \mathrm{~F}$ & Acromegaly & 4.82 & 245 & 199 & 98 \\
\hline 18 & $58, \mathrm{M}$ & Nonfunctioning & 1.89 & 185 & 147 & 100 \\
\hline 19 & $46, \mathrm{M}$ & Plurihormonal adenoma & 3.56 & 150 & 164 & 100 \\
\hline 20 & $71, \mathrm{~F}$ & Plurihormonal adenoma & 2.28 & 163 & 157 & 100 \\
\hline 21 & $41, \mathrm{M}$ & Pituitary apoplexy & 2.57 & 134 & 119 & 100 \\
\hline 22 & $65, \mathrm{~F}$ & Plurihormonal adenoma & 0.91 & 353 & 145 & 100 \\
\hline 23 & $66, \mathrm{M}$ & Plurihormonal adenoma & 3.23 & 345 & 120 & 100 \\
\hline 24 & $56, \mathrm{~F}$ & Plurihormonal adenoma & 0.84 & 180 & 123 & 100 \\
\hline 25 & $62, \mathrm{~F}$ & Mixed GH \& PRL adenoma & 0.32 & 100 & 119 & 100 \\
\hline 26 & $70, \mathrm{M}$ & Plurihormonal adenoma & 5.86 & 350 & 191 & 100 \\
\hline 27 & $81, \mathrm{M}$ & Plurihormonal adenoma & 3.63 & 120 & 155 & 100 \\
\hline 28 & $81, \mathrm{M}$ & Somatotroph cell adenoma & 11.02 & 535 & 190 & 95 \\
\hline 29 & $55, \mathrm{~F}$ & Plurihormonal adenoma & 6.55 & 135 & 148 & 100 \\
\hline 30 & $32, \mathrm{~F}$ & Plurihormonal adenoma & 0.19 & 100 & 116 & 100 \\
\hline
\end{tabular}


of bridging therapy is rarely mentioned in cases of internal carotid artery dissection, ${ }^{40}$ as is placement of cutaneousventricular drainage for patients after intravascular treatment ${ }^{41}$ However, these cases do not provide a high level of medical evidence.

The present cohort study was performed at a single institution and by a single surgeon. The protocol was simple, as neither discontinuation of antithrombotic therapy nor introduction of bridging therapy was required. Therefore, the treatment and control groups were easily compared. However, the true implications cannot be fully clarified, and validation of this protocol is limited only to extraarachnoid, typical transsphenoidal surgeries. Large randomized clinical trials at multiple centers are essential to recommend standardization of this management for patients receiving antithrombotic therapy. Although patients receiving antithrombotic therapy should only undergo transsphenoidal surgery when absolutely necessary, various types of procedures should be investigated to establish a high level of medical evidence about this increasing problem in the neurosurgical field.

\section{Conclusions}

Transsphenoidal surgeries were performed in 15 patients without discontinuation of antithrombotic therapy. No patient required transfusion, and intraoperative bleeding, operation time, and tumor removal rate showed no significant differences between these patients and the control group. The present study suggests that discontinuation of antithrombotic therapy may be unnecessary before the typical transsphenoidal surgery. Large randomized clinical trials are needed to establish validation of this procedure.

\section{References}

1. Ah-Weng A, Natarajan S, Velangi S, Langtry JA: Preoperative monitoring of warfarin in cutaneous surgery. Br J Dermatol 149:386-389, 2003

2. Alam M, Goldberg LH: Serious adverse vascular events associated with perioperative interruption of antiplatelet and anticoagulant therapy. Dermatol Surg 28:992-998, 2002

3. Alcalay J: Cutaneous surgery in patients receiving warfarin therapy. Dermatol Surg 27:756-758, 2001

4. Armstrong MJ, Gronseth G, Anderson DC, Biller J, Cucchiara B, Dafer R, et al: Summary of evidence-based guideline: periprocedural management of antithrombotic medications in patients with ischemic cerebrovascular disease: report of the Guideline Development Subcommittee of the American Academy of Neurology. Neurology 80:2065-2069, 2013

5. Baron TH, Kamath PS, McBane RD: Management of antithrombotic therapy in patients undergoing invasive procedures. N Engl J Med 368:2113-2124, 2013

6. Billingsley EM, Maloney ME: Intraoperative and postoperative bleeding problem in patients taking warfarin, aspirin, and nonsteroidal anti-inflammatory agents. A prospective study. Dermatol Surg 23:381-383, 1997

7. Cannon PD, Dharmar VT: Minor oral surgical procedures in patients on oral anticoagulants-a controlled study. Aust Dent J 48:115-118, 2003

8. Carrel TP, Klingenmann W, Mohacsi PJ, Berdat P, Althaus $\mathrm{U}$ : Perioperative bleeding and thromboembolic risk during non-cardiac surgery in patients with mechanical prosthetic heart valves: an institutional review. J Heart Valve Dis 8:392-398, 1999
9. Carter K, Miller KM: Phacoemulsification and lens implantation in patients treated with aspirin or warfarin. J Cataract Refract Surg 24:1361-1364, 1998

10. Custer PL, Trinkaus KM: Hemorrhagic complications of oculoplastic surgery. Ophthal Plast Reconstr Surg 18:409415, 2002

11. Devani P, Lavery KM, Howell CJ: Dental extractions in patients on warfarin: is alteration of anticoagulant regime necessary? Br J Oral Maxillofac Surg 36:107-111, 1998

12. Devereaux PJ, Mrkobrada M, Sessler DI, Leslie K, AlonsoCoello P, Kurz A, et al: Aspirin in patients undergoing noncardiac surgery. N Engl J Med 370:1494-1503, 2014

13. Dunn AS, Turpie AG: Perioperative management of patients receiving oral anticoagulants: a systematic review. Arch Intern Med 163:901-908, 2003

14. Evans IL, Sayers MS, Gibbons AJ, Price G, Snooks H, Sugar AW: Can warfarin be continued during dental extraction? Results of a randomized controlled trial. Br J Oral Maxillofac Surg 40:248-252, 2002

15. Gainey SP, Robertson DM, Fay W, Ilstrup D: Ocular surgery on patients receiving long-term warfarin therapy. Am J Ophthalmol 108:142-146, 1989

16. Hall DL, Steen WH Jr, Drummond JW, Byrd WA: Anticoagulants and cataract surgery. Ophthalmic Surg 19:221-222, 1988

17. Kallio H, Paloheimo M, Maunuksela EL: Haemorrhage and risk factors associated with retrobulbar/peribulbar block: a prospective study in 1383 patients. Br J Anaesth 85:708711,2000

18. Katholi RE, Nolan SP, McGuire LB: Living with prosthetic heart valves. Subsequent noncardiac operations and the risk of thromboembolism or hemorrhage. Am Heart J 92:162167,1976

19. Katz J, Feldman MA, Bass EB, Lubomski LH, Tielsch JM, Petty BG, et al: Risks and benefits of anticoagulant and antiplatelet medication use before cataract surgery. Ophthalmology 110:1784-1788, 2003

20. Kim DJ, Suh SH, Kim BM, Kim DI, Huh SK, Lee JW: Hemorrhagic complications related to the stent-remodeled coil embolization of intracranial aneurysms. Neurosurgery 67:73-79, 2010

21. Lip GYH, Durrani OM, Roldan V, Lip PL, Marin F, Reuser TQ: Peri-operative management of ophthalmic patients taking antithrombotic therapy. Int J Clin Pract 65:361-371, 2011

22. McCormack P, Simcock PR, Tullo AB: Management of the anticoagulated patient for ophthalmic surgery. Eye (Lond) 7:749-750, 1993

23. McMahan LB: Anticoagulants and cataract surgery. J Cataract Refract Surg 14:569-571, 1988

24. Morris A, Elder MJ: Warfarin therapy and cataract surgery. Clin Experiment Ophthalmol 28:419-422, 2000

25. Narendran N, Williamson TH: The effects of aspirin and warfarin therapy on haemorrhage in vitreoretinal surgery. Acta Ophthalmol Scand 81:38-40, 2003

26. Niemi T, Armstrong E: Thromboprophylactic management in the neurosurgical patient with high risk for both thrombosis and intracranial bleeding. Curr Opin Anaesthesiol 23:558-563, 2010

27. Niemi T, Silvasti-Lundell M, Armstrong E, Hernesniemi J: The Janus face of thromboprophylaxis in patients with high risk for both thrombosis and bleeding during intracranial surgery: report of five exemplary cases. Acta Neurochir (Wien) 151:1289-1294, 2009

28. Ortel TL: Perioperative management of patients on chronic antithrombotic therapy. Hematology (Am Soc Hematol Educ Program) 2012:529-535, 2012

29. Otley CC, Fewkes JL, Frank W, Olbricht SM: Complications of cutaneous surgery in patients who are taking warfarin, 
aspirin, or nonsteroidal anti-inflammatory drugs. Arch Dermatol 132:161-166, 1996

30. Palareti G, Legnani C: Warfarin withdrawal. Pharmacokinetic-pharmacodynamic considerations. Clin Pharmacokinet 30:300-313, 1996

31. Panczykowski DM, Okonkwo DO: Premorbid oral antithrombotic therapy and risk for reaccumulation, reoperation, and mortality in acute subdural hematomas. J Neurosurg 114:47-52, 2011

32. Roberts CW, Woods SM, Turner LS: Cataract surgery in anticoagulated patients. J Cataract Refract Surg 17:309-312, 1991

33. Robinson GA, Nylander A: Warfarin and cataract extraction. Br J Ophthalmol 73:702-703, 1989

34. Rotenstreich Y, Rubowitz A, Segev F, Jaeger-Roshu S, Assia EI: Effect of warfarin therapy on bleeding during cataract surgery. J Cataract Refract Surg 27:1344-1346, 2001

35. Saitoh AK, Saitoh A, Taniguchi H, Amemiya T: Anticoagulation therapy and ocular surgery. Ophthalmic Surg Lasers 29:909-915, 1998

36. Schanbacher CF, Bennett RG: Postoperative stroke after stopping warfarin for cutaneous surgery. Dermatol Surg 26:785-789, 2000

37. Shalom A, Wong L: Outcome of aspirin use during excision of cutaneous lesions. Ann Plast Surg 50:296-298, 2003

38. Shuler JD, Paschal JF, Holland GN: Antiplatelet therapy and cataract surgery. J Cataract Refract Surg 18:567-571, 1992

39. Souto JC, Oliver A, Zuazu-Jausoro I, Vives A, Fontcuberta J: Oral surgery in anticoagulated patients without reducing the dose of oral anticoagulant: a prospective randomized study. J Oral Maxillofac Surg 54:27-32, 1996

40. Suyama K, Hayashi K, Nagata I: [Cervicocephalic arterial dissection.] Brain Nerve 60:1115-1123, 2008 (Jpn)

41. Sweeney JM, Vasan R, van Loveren HR, Youssef AS, Agazzi $\mathrm{S}$ : Catheter fixation and ligation: a simple technique for ventriculostomy management following endovascular stenting. J Neurosurg 118:1009-1013, 2013

42. Wong JM, Ziewacz JE, Panchmatia JR, Bader AM, Pandey AS, Thompson BG, et al: Patterns in neurosurgical adverse events: endovascular neurosurgery. Neurosurg Focus 33(5):E14, 2012

\section{Author Contributions}

Conception and design: Ogawa. Acquisition of data: Ogawa. Analysis and interpretation of data: Ogawa. Drafting the article: Ogawa. Critically revising the article: both authors. Reviewed submitted version of manuscript: Tominaga. Approved the final version of the manuscript on behalf of both authors: Ogawa. Statistical analysis: Ogawa. Administrative/technical/material support: Ogawa. Study supervision: Tominaga.

\section{Correspondence}

Yoshikazu Ogawa, Department of Neurosurgery, Kohnan Hospital, 4-20-1 Nagamachiminami, Taihaku-ku, Sendai, Miyagi 982-8523, Japan. email: yogawa@kohnan-sendai.or.jp. 